\title{
Variables Associated with Severity of Bacterial Canker and Wilt Caused by Clavibacter michiganensis subsp. michiganensis in Tomato Greenhouses
}

\author{
L. Blank, Y. Cohen, M. Borenstein, R. Shulhani, M. Lofthouse, M. Sofer, and D. Shtienberg
}

First, third, fourth, fifth, and seventh authors: Department of Plant Pathology and Weed Research, ARO, Volcani Center, Bet Dagan, 50250, Israel; second author: Institute of Agricultural Engineering, ARO, Volcani Center, Bet Dagan 50250, Israel; and fifth and sixth authors: Negev R\&D Center, D.N. Negev, 85400, Israel.

Accepted for publication 15 November 2015.

\begin{abstract}
Blank, L., Cohen, Y., Borenstein, M., Shulhani, R., Lofthouse, M., Sofer, M., and Shtienberg, D. 2016. Variables associated with severity of bacterial canker and wilt caused by Clavibacter michiganensis subsp. michiganensis in tomato greenhouses. Phytopathology 106:254-261.

Clavibacter michiganensis subsp. michiganensis, the causal agent of bacterial canker and wilt of tomato, is considered to be one of the most important bacterial pathogens worldwide. In the year 2000 there was an increase in the number of infected greenhouses and in the severity of the disease in Israel. As part of the effort to cope with the disease, a comprehensive survey was conducted. Scouts recorded disease severity monthly in 681 production units. At the end of the season the scouts met with the growers and together recorded relevant details about the crop and cultural practices employed. The results suggested an absence of anisotropy pattern in

the study region. Global Moran's I analysis showed that disease severity had significant spatial autocorrelation. The strongest spatial autocorrelation occurred within a $1,500 \mathrm{~m}$ neighborhood, which is comparable to the distance between production units maintained by one grower (Farm). Next, we tested three groups of variables including or excluding the Farm as a variable. When the Farm was included the explained variation increased in all the studied models. Overall, results of this study demonstrate that the most influential factor on bacterial canker severity was the Farm. This variable probably encompasses variation in experience, differences in agricultural practices between growers, and the quality of implementation of management practices.

Additional keywords: geostatistics, hierarchical partitioning, Solanum lycopersicum.
\end{abstract}

One of the major goals of epidemiological research is to find the variables affecting the spread or severity of diseases (Campbell and Madden 1990). Observational studies that are based on data collected in field surveys, compromise the a priori control, inherent to experimental design, for a large number of surveyed plots. This provides such studies enough statistical power while enabling the assessment of the disease under real field conditions. Both are crucial when the knowledge of the biological system is lacking. Studies based on large-scale surveys are not common for emerging infectious diseases (Meentemeyer et al. 2012) and mostly focus on correlating disease incidence with environmental (e.g., soil type and $\mathrm{pH}$ ) and climatic conditions (Aguayo et al. 2014; Lamichhane et al. 2014). Only a few such studies have explored the relationship between disease incidence and variability associated with the agricultural practices employed and the management decisions made, such as selection of growth type, source of the seedlings and the time between cropping cycles (Shtienberg 1996; Thébaud et al. 2006).

Tomato crops (Solanum lycopersicum) are one of the main vegetable crops in Israel. Most (77\% of ca. 5,000 ha) are grown in polyethylene covered greenhouses or net-houses (referred to hereafter as production units) to avoid infestation by Bemisia tabaci, the vector of the Tomato yellow leaf curl virus. Transplants are planted directly in the soil, irrigated via drip irrigation and maintained according to the single-stem trellising system. The main regions of tomato production are in the northwestern Negev, a semiarid zone, comprising $70 \%$ of the production under cover in Israel (Fig. 1). In that region, tomatoes are planted year-round but most plantings are in the autumn (September to November) for the

Corresponding author: L. Blank; E-mail address: liorb@volcani.agri.gov.il

http://dx.doi.org/10.1094/PHYTO-07-15-0159-R

(C) 2016 The American Phytopathological Society winter-spring harvest season and in the spring (February to May) for the summer-autumn season. Tomato growers specialize and generally cultivate tomatoes in monoculture rotation, i.e., tomatoes follow tomatoes.

Clavibacter michiganensis subsp. michiganensis, the causal agent of bacterial canker and wilt of tomato (S. lycopersicum), is considered to be one of the most important bacterial pathogens worldwide (Eichenlaub and Gartemann 2011). C. michiganensis subsp. michiganensis was recorded in Israel in 1963 and has appeared sporadically since then (Volcani 1985). Severe epidemics occurred in the year 2000 (Kleitman et al. 2008) and also in 2005 to 2007 resulting in substantial yield losses in many greenhouses (D. Shtienberg, unpublished data). Resistant cultivars would be an effective method for disease control. However, currently no resistant commercial cultivars are available (Sen et al. 2015). As there were no effective means to control the disease (Sen et al. 2015), the Ministry of Agriculture and Rural Development together with the Council of Vegetable Growers initiated a national research project. The goal was to develop effective means of bacterial canker suppression in the regions of tomato production where the disease was already established, and prevent its spread to other regions of tomato production. Observations carried out prior to commencement of the project suggested that prevalence and severity of bacterial canker varied markedly between tomato production units, even between those located in close proximity (D. Shtienberg, unpublished data). It was hypothesized that identifying the factors governing this variability would enable development of effective means for disease suppression.

Primary inoculum of $C$. michiganensis subsp. michiganensis can originate within or outside the production unit. Within the unit the pathogen can persist in plant debris, in soil, and on contaminated greenhouse structures (Fatmi and Schaad 2002; Strider 1969) and can potentially survive on trellising strings or on irrigation pipes. C. michiganensis subsp. michiganensis can survive for several 
months in tomato debris buried in the soil (Basu 1970) but survival duration depends on the environmental conditions (Yogev et al. 2009). Thus, bacterial canker severity in the previous cropping cycle, and the time lapse between cycles, might have an effect on the severity of the disease in the current cycle. In addition, cultural practices employed between cropping cycles such as solarization and sanitation procedures may be effective in reducing $C$. michiganensis subsp. michiganensis survival (Shlevin et al. 2004).

Variables related to primary inoculum originating from outside the production unit include infection from already infected production units and crop waste dumps. The potential for longterm survival of $C$. michiganensis subsp. michiganensis in infected tomato stems or leaves has been shown (Gleason et al. 1991). However, to our knowledge there is no documentation of wind dispersal of the disease. In addition, primary infections in many countries were attributed to the introduction of contaminated tomato seeds and/or seedlings (Gitaitis et al. 1991; Kleitman et al. 2008).

C. michiganensis subsp. michiganensis is a polycyclic pathogen, and plants infected from the primary sources of inoculum can be the source of secondary spread to nearby healthy plants during the growing season. Epiphytic C. michiganensis subsp. michiganensis cells may be dispersed by splashing rain or droplets from overhead irrigation or chemical spraying (Strider 1967). However, the main mechanisms of secondary spread are believed to be disbudding and removal of the lower leaves either manually or with tools, and pesticide spraying (Gleason et al. 1993). During trimming of infected plants the tools used become contaminated with the bacteria. Wounds created in nearby healthy plants are suitable infection sites for the pathogen. Furthermore, it has been shown that touching infected plants bearing guttation droplets infested with C. michiganensis subsp. michiganensis, prior to touching neighboring plants transfers the pathogen, which is exuded in the guttation fluid (Sharabani et al. 2013). The guttation phenomenon is affected by a number of factors such as humidity, temperature, growth stage, and water stress (Tapparo et al. 2011) and thus is expected to vary

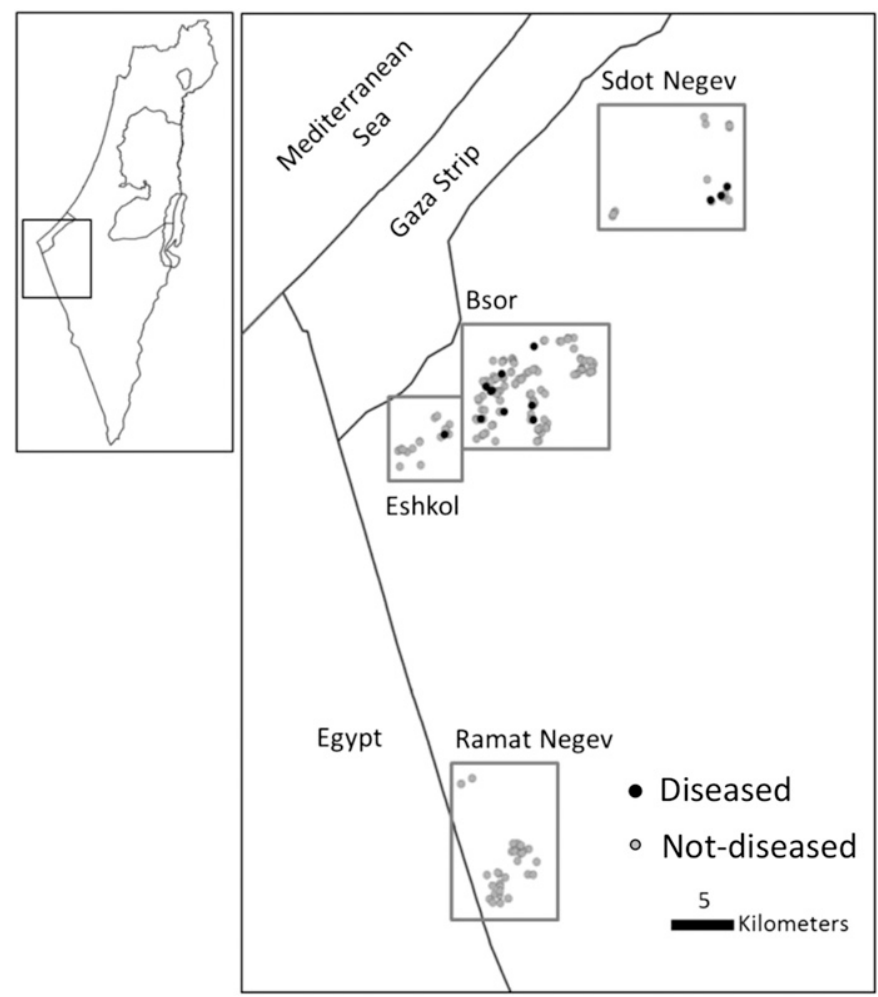

Fig. 1. Map of the locations of the four counties and production units, displaying the survey of plants transplanted between January 2010 and July 2010 $(n=172)$. Square on the left map indicates the study area. between seasons and over time. Under suitable conditions the pathogen can invade the target plants through stomata, trichomes, or hydathodes, leading to infections (Gleason et al. 1993).

A thorough study examining different predictors of the C. michiganensis subsp. michiganensis disease severity both within and outside the production unit, and during the growing season, has not been conducted. Much is known about the pathogen and the epidemiology of the disease (Sen et al. 2015). However, most studies have been carried out on processing tomatoes and fresh market tomatoes grown outdoors. The epidemiology of bacterial canker in greenhouses has received little attention and research to elucidate the mechanisms of spread of the pathogen in the greenhouse environment is a top priority of the tomato industry (Gleason et al. 1993). This is still valid; thus, studying the epidemiology of the disease was a prerequisite for attaining the project goal. Accordingly, a comprehensive survey was conducted in tomato production units during the years 2008 to 2011 in the northwestern Negev. The survey had two objectives: (i) to document the prevalence and characterize the spatial pattern of disease in the main regions of tomato production of the country and (ii) to identify the effects and relative significance of cultural and management practices used by commercial growers on disease severity.

\section{MATERIALS AND METHODS}

Survey description. The survey was conducted between 2008 and 2011 in the southwestern part of Israel in four counties: Ramat Negev, Eshkol, Bsor, and Sdot Negev (Fig. 1 and Table 1). These are the main regions of tomato production in Israel. Extension officers working in these counties identified the villages and farms to be included in the survey. Attempts were made to include production units in all villages where tomatoes are grown. The aim of the survey was to document the prevalence of the disease and its severity in tomatoes maintained under a wide range of physical, climatic, cultural, and management conditions rather than to accurately estimate the severity of the disease in the surveyed area. The extension officers contacted tomato growers in the regions and asked them to participate in the survey. The survey was carried out in the production units belonging to growers who agreed to cooperate. These growers exhibited a range of expertise, and professionalism representative of many other growers. The survey encompassed 681 production units in total (666.3 ha). Whenever possible, the same production units were inspected in consecutive cropping cycles; in 53 production units the survey was carried out in two consecutive production cycles, and in 85 production units the survey was carried out in $\geq 3$ consecutive cropping cycles. The survey period was divided into eight subperiods according to the months of transplanting (Table 1). The surveyed area varied between subperiods and ranged between 2 to $20 \%$ of the total tomato production area of these regions.

Scouts, hired for the project, visited each of the surveyed production units beginning approximately 1 month after transplanting, and thereafter in monthly intervals until the end of cropping cycle. The same scouts took part in this survey throughout the study. Before the

TABLE 1. The number of production units and the area they covered in the eight subperiods of the bacterial canker survey

\begin{tabular}{lcc}
\hline $\begin{array}{l}\text { Survey subperiod } \\
\text { (transplanting period) }\end{array}$ & $\begin{array}{c}\text { Number of surveyed } \\
\text { production units }\end{array}$ & $\begin{array}{c}\text { Surveyed area } \\
\text { (ha) }\end{array}$ \\
\hline Aug. 2008 to Dec. 2008 & 24 & 16.3 \\
Jan. 2009 to Jun. 2009 & 90 & 83.3 \\
Jul. 2009 to Dec. 2009 & 73 & 64.4 \\
Jan. 2010 to Jun. 2010 & 172 & 188.8 \\
Jul. 2010 to Dec. 2010 & 140 & 121.5 \\
Jan. 2011 to Jun. 2011 & 90 & 105.9 \\
Jul. 2011 to Dec. 2011 & 69 & 68.5 \\
Jan. 2011 to Jun. 2011 & 22 & 17.6 \\
\hline
\end{tabular}


beginning of the survey they were trained to identify the disease. In order to ensure a high degree of consistency between them, we carried out a pilot exercise, in which some production units were surveyed independently by all scouts. In each production unit the scouts walked between the rows observing the foliage, and looking for the typical symptoms of bacterial canker. The route in each production unit was arbitrary and differed in each assessment. The survey in each production unit lasted between 20 to $40 \mathrm{~min}$, depending on the size of the unit. Disease severity was recorded on a whole production unit basis, using a scale with six levels as follows: 0, no disease (symptomatic plants were not observed in the production unit); 1 , very low severity (few plants exhibited foliar symptoms; wilting plants were not observed); 2 , low severity (up to $5 \%$ of the plants exhibited foliar symptoms, few wilted plants); 3 , moderate severity (5 to $30 \%$ of the plants exhibited foliar symptoms; up to $5 \%$ of the plants wilted); 4 , high severity (more than $30 \%$ of the plants exhibited foliar symptoms; 5 to $30 \%$ of the plants wilted); and 5, very high severity (most of the plants exhibited foliar symptoms or wilt). We used this category scales method as it is easy to learn and use and provides a rapid way of assessing large number of units, as is required when covering large areas for spatial studies or when trying to capture a wide range of predictors. The geographic location of each production unit was recorded when it was sampled using GPS. Upon first identification of typical disease symptoms in a production unit or if uncertainty arose regarding identification of the disease, a sample was analyzed using Immuno Strips for $C$. michiganensis subsp. michiganensis (Agdia, Elkhart, IN). In addition, samples from symptomatic plants were plated on $\mathrm{m}$-CNS plates as described by Sharabani et al. (2013). Suspicious colonies were identified using primers PCF3 and PCF5 of the celA CB domain and primers $\mathrm{P} 5$ and $\mathrm{P} 6$ of the pat- 1 gene as described by Kleitman et al. (2008).

Spatial patterns of the disease in the main regions of tomato production of the country. Geostatistic analysis was applied to quantify the range of variability of disease severity for each of the survey subperiods. Semivariance analysis examines the contribution of all pairs of points that are separated by a given distance (lag) to the total sample variance (Legendre and Legendre 2012). The degree of anisotropy, or directional spatial dependence, was examined for disease severity at directions of 0 , 45,90 , and $135^{\circ}$. This analysis was done using GS+ (Gamma Design Software, Plainwell, MI). The anisotropy ratio is the ratio between the slopes of the directions in maximum and minimum variations (Trangmar et al. 1985). Most geostatistic analyses have considered anisotropy ratios less than 2.5 as the indication of no significant anisotropy (Rouhani et al. 1996; Wang et al. 2002).

We applied Moran's I autocorrelation analysis (Kalkhan 2011; Legendre and Legendre 2012; Moran 1950) to each of the eight survey subperiods using the ArcGIS software (ESRI, Redlands, CA). This analysis is intended to recognize and quantitatively characterize patterns of spatial dependence between the sites. In our work, a positive Moran's $I$ value indicates that nearby greenhouses have similar severity values for bacterial canker prevalence, thus indicating spatial autocorrelation and clustering.

To reveal the distance where the spatial processes responsible for clustering are the most pronounced we used Incremental Spatial Autocorrelation tool (ArcGIS, ESRI, Redlands, CA) (ESRI 2015), by determining the distance at which the Z-score peaks (Pierre et al. 2014; Tan and Li 2014). This method calculates the global Moran's I at a series of incremental distances. Z-score associated with each global Moran's $I$ value is then calculated at each distance increment. Z-score peaks reflect distances where the spatial processes promoting clustering was most pronounced (ESRI 2015). For this analysis we took only production units that overlap temporally. Thus, we focused on the survey periods starting in January 2010 until June 2011. Crops last between 6 to 9 months; thus, in such a short period there is high level of overlap between units. We calculated it from 500 to $5,000 \mathrm{~m}$ using a distance increment of $500 \mathrm{~m}$. The initial distance and distance increments of $500 \mathrm{~m}$ were selected as this was the shortest distance/increment in which a suitable number of production units had neighbors in all distances $(500,1,000,1,500 \mathrm{~m} \ldots)$ allowing the calculations of the Z-score. Significant first peaks of Z-scores signify where spatial processes promoting clustering are most pronounced. Generally, the Z-scores peak associated with larger distances indicate general distribution trends, while peaks at smaller distances could indicate local variations. The distance where the first Z-score peak occurs was considered for the spatial analysis.

In order to determine the level of variation potentially associated with experience and differences in agricultural practices between growers, we also used the variables Farm (production units maintained by one grower), Village (settlements that include a few to dozens of farms that belong to the same local municipality), and County. To get the estimated scale distance for each of these hierarchical levels we averaged the average distance between any two units within each farm, village, or county.

The relative significance of cultural and management practices on disease severity. At the end of the growing cycle the scouts completed a questionnaire together with the growers, and the relevant details regarding the crop and the cultural practices employed were recorded. The database was organized in records and each record includes all the information collected for a specific production unit. A production unit that was planted, harvested and then replanted during the survey was considered as two unique records. The variables collected and quantified by the scouts were divided into three groups (Table 2). The first group consisted of variables related to primary inoculum originating within the production unit. These included: the preceding crop (tomato, other crops or a newly constructed production unit) (hereafter, FormerCrop), severity of bacterial canker in the previous cropping cycle (PriorSeverity), the elapsed time from the previous cropping cycle (DeltaDates), application of pesticides into the soil (Pesticide), soil solarization (Solarization) and implementation of sanitation, including whole structure disinfection and/or replacement of the trellising strings and irrigation pipes (Sanitation). The second group consisted of variables related to primary inoculum originated outside the production unit. These included distance to nearest infected production unit in the same cropping cycle (DistInfected), distance to nearest agriculture trash dumps (distTrash), and the source of the seedlings (Nursery). The third group consisted of variables related to disease development during the growing season. These included the type of the production unit (greenhouse or net-house) (UnitType), the cultivar (Cultivar), month of transplanting (TranspMonth), implementation of management practices to minimize disease spread and severity, such as removing symptomatic plants or spraying of copper products (mainly Kocide) during the season (Management), and avoiding working while the plants bear guttation droplets (WorkDry). The later variable was included as it was found that when symptomless source plants wet with guttation droplets were touched, subsequent touching of adjacent plants could spread the bacteria along rows to long distances (Sharabani et al. 2013).

We tested all the variables for multicollinearity by examining cross-correlations among variables (Graham 2003). Crosscorrelation between the variables belonging to the same variables group were lower than 0.65 . The dependent variable was maximum severity, i.e., the highest level of severity observed for each production unit in a single cropping cycle. To get a better understanding of the independent contribution of each variable we used hierarchical partitioning using the package Hier.Part 
(MacNally and Walsh 2004). Hierarchical partitioning decomposes the variation contained in response variables into independent components which reflect the relative importance of individual variables and their joint effects by considering all possible models. This process involved computation of the increase in the fit of all models with a particular variable compared with model without that variable, and averaging the improvement in fit across all possible models which include that variable. Statistical significances of the independent contributions of variables were tested by a randomization with 499 repetitions using the function rand.hp. Given the spatial autocorrelation we identified, we took it into account by adding an autocovariate term to our models (Dormann et al. 2007) using the function autocov_dist within the package of spdep in R 3.1.0 (R Core Development Team) (Bivand et al. 2011) (hereafter, Autocor). We calculated $R^{2}$ N values (Nagelkerke 1991) using the package PredictABEL (Kundu et al. 2011).

\section{RESULTS}

Spatial patterns of the disease in the main regions of tomato production of the country. Out of the 681 surveyed production units, 253 (38\%) were diseased. We used semivariance analysis to examine the degree of anisotropy (directional spatial dependence) at directions of $0^{\circ}, 45^{\circ}, 90^{\circ}$, and $135^{\circ}$. The anisotropy ratio, given by the relation between the lengths of the maximum and minimum anisotropy semiaxes, had a value of $\cong 1$ for all survey periods, suggesting an absence of anisotropy in the study regions. For six of the eight survey subperiods, global Moran's I analysis showed that disease severity had significant spatial autocorrelation $(P \leq 0.05)$, revealing the existence of potential clustered spatial patterns (Table 3).

We then tested for spatial autocorrelation at $500 \mathrm{~m}$ distance intervals using Moran's $I$. The first Z-score peak representing the distance where the spatial processes promote clustering occurred within a $1,500 \mathrm{~m}$ neighborhood (Z-score $=10.54 ; P<0.0001)$ (Fig. 2 ). We then compared it to the average distance between production units within the three spatial scales. County had an average distance between production units of 4,278 $\pm 925 \mathrm{~m}$. For Village and Farm the average distances between production units were 1,528 \pm 234 and 1,594 \pm $246 \mathrm{~m}$, respectively. As the distance at which the spatial processes promote clustering $(1,500 \mathrm{~m})$ resembled the average distances between production units within villages and/or within farms, we then attempted to identify the scale parameter related to clustering.

To elucidate if clustering resulted from factors related to the Farm, we examined the spatial distribution of diseased and nondiseased production units maintained by individual growers. Significant differences in disease prevalence and severity were observed between farms, including cases where production units of two neighboring farms were in close proximity or even

TABLE 3. Global Moran's $I$ analysis results for each of the eight survey subperiods

\begin{tabular}{lcccl}
\hline $\begin{array}{l}\text { Survey subperiod } \\
\text { transplanting period) }\end{array}$ & Moran's $I$ & Z-value & $P$ value & Pattern \\
\hline Aug. 2008 to Dec. 2008 & 0.565 & 1.49 & 0.135 & Random \\
Jan. 2009 to Jun. 2009 & 0.617 & 2.61 & 0.009 & Clustered \\
Jul. 2009 to Dec. 2009 & 0.676 & 2.20 & 0.02 & Clustered \\
Jan. 2010 to Jun. 2010 & 0.653 & 3.13 & 0.002 & Clustered \\
Jul. 2010 to Dec. 2010 & 0.487 & 2.83 & 0.005 & Clustered \\
Jan. 2011 to Jun. 2011 & 0.993 & 3.74 & $<0.001$ & Clustered \\
Jul. 2011 to Dec. 2011 & 0.244 & 1.02 & 0.306 & Random \\
Jan. 2011 to Jun. 2011 & 0.950 & 2.51 & 0.012 & Clustered \\
\hline
\end{tabular}

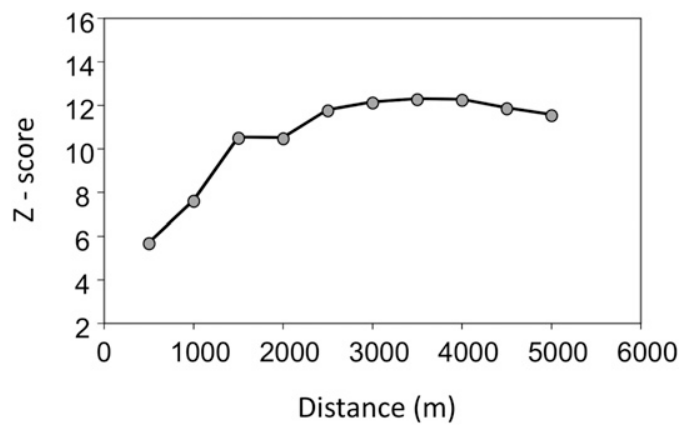

Fig. 2. Results of the incremental spatial autocorrelation analysis. The graph shows the Z-score for each distance increment. Filled circles represent significant $Z$-score values $(P<0.05)$.

TABLE 2. The variables used in the study

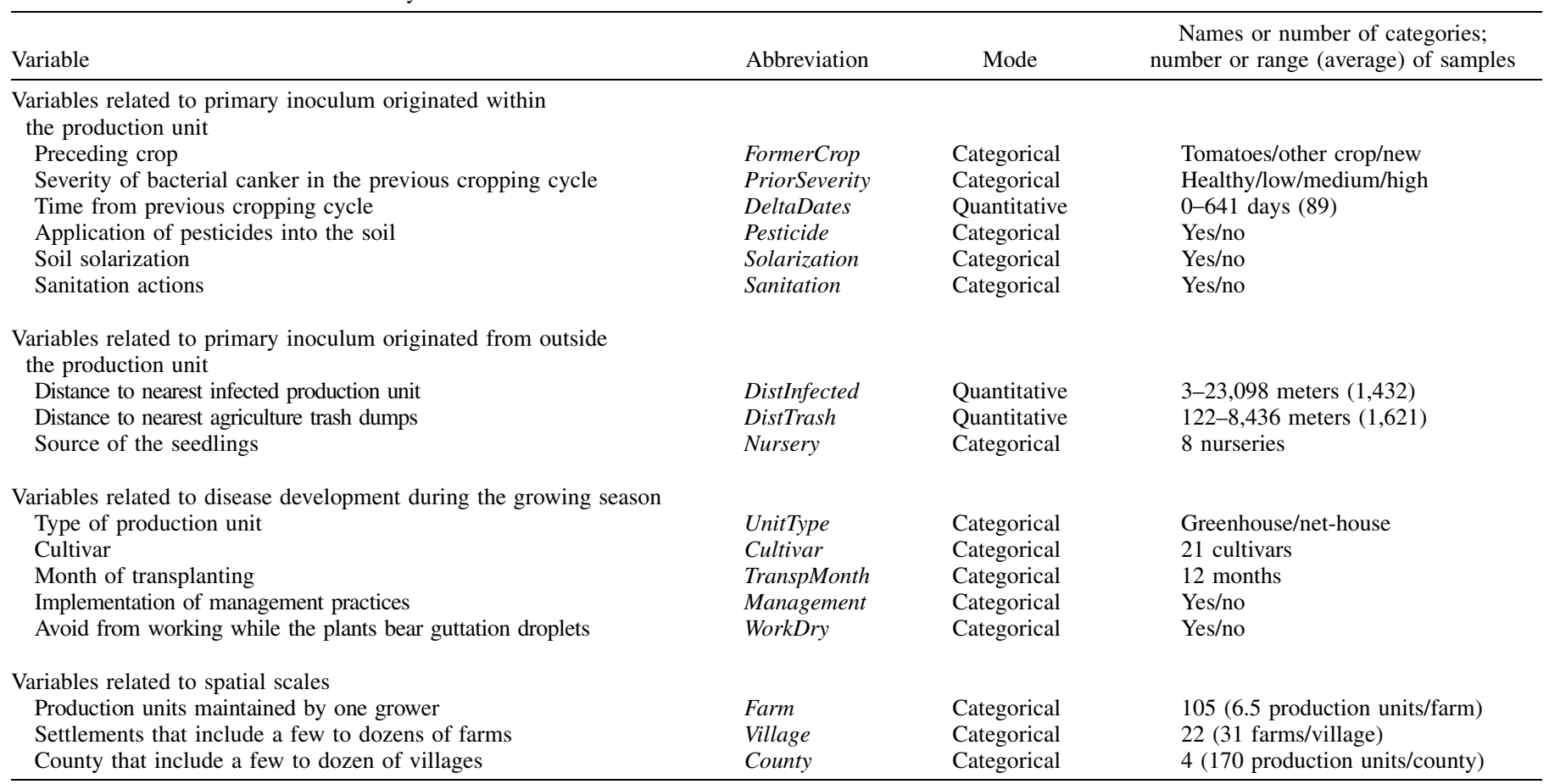


intertwined. An example recorded in the survey subperiod of January 2011 to June 2011 in a distinct area is presented in Figure 3 . In that area the survey was carried out in production units of four farms. Farm A had nine production units; disease was observed in eight of them. Farm B had six production units and the disease was observed in only one production unit and farms $\mathrm{C}$ and $\mathrm{D}$ had three and two production units, respectively, of which none were diseased. Some of the production units of farm A were in close proximity (170 to $450 \mathrm{~m}$ ) to the nondiseased units of other farms (Fig. 3).

The relative significance of cultural and management practices on disease severity. We investigated the contribution of each variable to bacterial canker severity using hierarchical partitioning. Our initial analyses were performed excluding the scale variables (i.e., County, Village, or Farm). The first model that included variables related to primary inoculum which originated within the production unit explained $9 \%$ of the variation in disease severity with three significant variables: PriorSeverity $(30.5 \%$ independent contribution), Solarization (30.2\%), and Sanitation

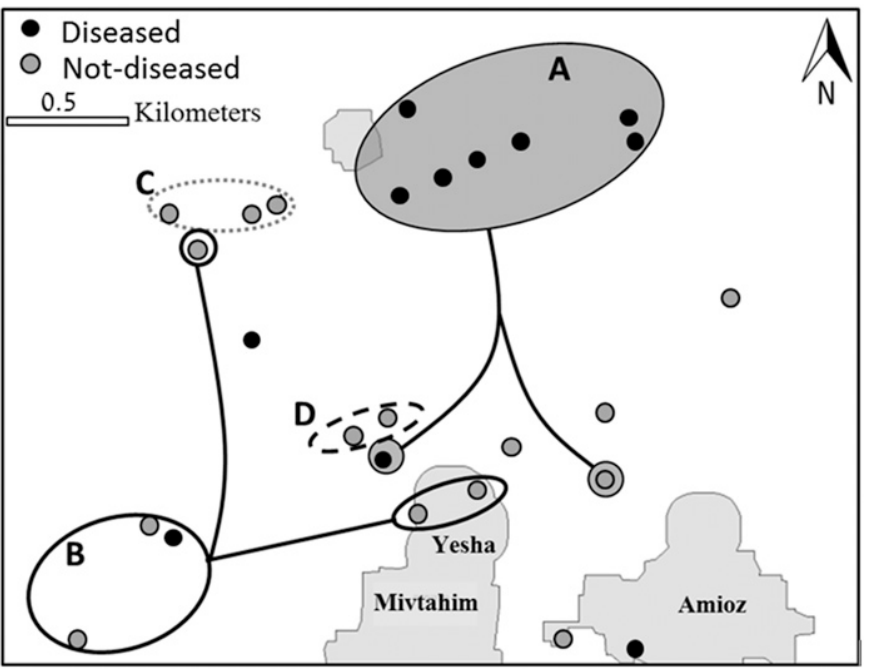

Fig. 3. An example of locations of diseased and not-diseased production units located in the vicinity of the villages Yesha, Mivtahim, and Amioz in Bsor County. Line patterns (dashed, doted, continues hollow, or gray filled) represent different farms. Continuous lines are used to connect production units belonging to the same farm, maintained by the same grower (marked by capital letters, A to D).
(23.9\%) (Table 4). The severity of the disease in the previous growing cycle significantly affected the severity of the disease in the succeeding cycle (Fig. 4A). For example, significantly more production units were not-diseased in one cropping cycle if they were also not diseased in the previous cropping cycle compared with those production units that were diseased in the previous cropping cycle. Similarly, significantly more production units were severely diseased in one cropping cycle if they were also severely diseased in the previous cropping cycle as compared with those that were not diseased in the previous cropping cycle. Nevertheless, it should be noted that about $50 \%$ of the production area that was severely diseased in one cropping cycle was not diseased in the succeeding cropping cycle, and that in about $5 \%$ of the production area severe infections developed although these production units were not diseased in the previous production cycle (Fig. 4A). In production units where Solarization or Sanitation was utilized prior to transplanting, the relative production area with high severity level was smaller compared with the area where these measures were not implemented (Fig. 4B and C).

The second model included variables related to primary inoculum originated from outside the production unit explained 0.04 of the variation with one significant variable, DistInfected. The independent contribution of this variable to the explained variance was $29.7 \%$ (Table 4 ). In general, the proximity to infected production units increased the probability that a certain production unit will be diseased; but the spatial coincidence was inexplicit (Fig. 4D).

The third model which included variables related to disease development during the growing season had explained 0.35 of the variation in disease severity with four significant variables: TranspMonth (39.3\% independent contribution), Management (18\%), UnitType (16.4\%), and WorkDry (15.7\%) (Table 4). Production units transplanted between January to June were markedly more diseased than those that were transplanted between July to December and production units transplanted between February to April were threatened the most (Fig. 5A). Due to the effect of transplanting month on disease severity, we checked if the other three variables were confounded with the period of transplanting and ran the third model separately for the two transplanting periods (viz., January to June and July to December). Unexpectedly, in the first period a larger area was severely diseased in production units where the growers attempted to suppress the disease and implemented management practices compared with production units where management practices were not implemented (Fig. 5B). To resolve this enigma, growers that reported that they had implemented management practices were interviewed once again. It turns out that

TABLE 4. The independent contribution of significant variables as determined by hierarchical partitioning and results of the randomization tests

\begin{tabular}{|c|c|c|c|c|c|}
\hline \multirow{2}{*}{$\begin{array}{l}\text { Model number and the variables } \\
\text { included in the models }\end{array}$} & \multirow[b]{2}{*}{ Significant variables ${ }^{a}$} & \multicolumn{4}{|c|}{ Scale variables included in the models ${ }^{b}$} \\
\hline & & None & County & Village & Farm \\
\hline \multirow{5}{*}{$\begin{array}{l}\text { Model 1: variables related to primary } \\
\text { inoculum originated within the production } \\
\text { unit }\end{array}$} & PriorSeverity & 30.5 & NS & 12.3 & NS \\
\hline & Solarization & 30.2 & 19.6 & 10.3 & 3.3 \\
\hline & Sanitation & 23.9 & 16.5 & 5.6 & 2.1 \\
\hline & + single scale variable & - & 28.0 & 63.2 & 87.3 \\
\hline & Full model $R^{2}$ & $0.09 *$ & $0.11 * * *$ & $0.22 * * *$ & $0.49 * * *$ \\
\hline \multirow{3}{*}{$\begin{array}{l}\text { Mode 2: variables related to primary } \\
\text { inoculum originated from outside the } \\
\text { production unit }\end{array}$} & DistInfected & 29.7 & NS & NS & 1.9 \\
\hline & + single scale variable & - & 59.6 & 81.8 & 91.6 \\
\hline & Full model $R^{2}$ & $0.04 \mathrm{NS}$ & $0.06 \mathrm{NS}$ & $0.12 * * *$ & $0.44 * * *$ \\
\hline \multirow{6}{*}{$\begin{array}{l}\text { Model 3: variables related to disease } \\
\text { development during the growing season }\end{array}$} & TranspMonth & 39.3 & 36.2 & 29.1 & 17.9 \\
\hline & Management & 18.0 & 16.5 & 11.2 & 5.8 \\
\hline & UnitType & 16.4 & 14.0 & 10.8 & 5.1 \\
\hline & WorkDry & 15.7 & 15.5 & 11.6 & 6.3 \\
\hline & + single scale variable & - & 7.0 & 26.8 & 57.0 \\
\hline & Full model $R^{2}$ & $0.35 * * *$ & $0.37 * * *$ & $0.45 * * *$ & $0.65 * * *$ \\
\hline
\end{tabular}

${ }^{a}$ Scale variables included in the models were County, Village, or Farm.

b Significant differences: *, $P<0.05$;**, $P<0.01$; and ***, $P<0.001$. NS, not significant. See Table 2 section for variable names abbreviations. 
the management practices were carried out only after they had observed severe bacterial canker infections in their production units. Thus, the management practices did not cause an increase in severity but were implemented primarily in more severely infected production units. The type of production unit and avoiding handling plants while they bear guttation droplets affected disease severity in the first transplanting period. Greenhouses had a significantly smaller proportion of the area with high disease severity compared with nethouses (Fig. 5C) and a smaller percentage of the area was infected with high disease severity even when growers handled plants when they were wet with guttation droplets (Fig. 5D).

We then analyzed the contribution of each of the spatial-scale variables, County, Village, or Farm to the three models. The variation explained by the three models increased as the hierarchical scale decreased. Incorporating County increased the explained variation only by a few percent. Compared with that, the explained variation doubled or more upon including Village as a scale variable. However, when Farm was included in each of the models, the explained variation increased notably more from $0.09,0.04$, and 0.35 to $0.49,0.44$, and 0.65 for the first, second, and third models, respectively. In each of these models the scale variable Farm had the highest independent contribution with 87.3,91.6, and $57.0 \%$ of the explained variability (Table 4).

\section{DISCUSSION}

Results of this study point to the same conclusion-bacterial canker severity is spatially clustered. The global Moran's I analysis showed that disease severity had significant spatial autocorrelation and the dominant pattern was recognized as clustered. In accordance with this result, the incremental spatial autocorrelation analysis revealed that the distance where the spatial processes responsible for clustering is the most pronounced was about $1,500 \mathrm{~m}$. Two alternative explanations might explain this spatial clustering. According to the first, this fine-scale clustering might be the result of disease dispersal. The second focuses on human

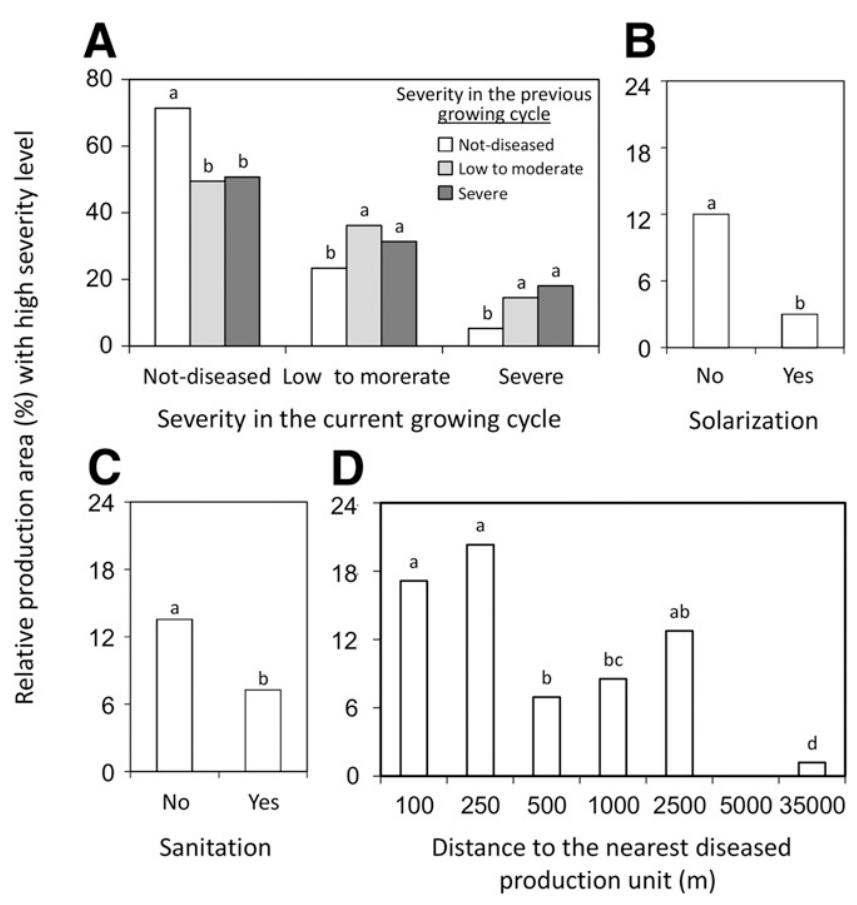

Fig. 4. Effects of the four significant variables from the first and second models on bacterial canker severity: $\mathbf{A}$, disease severity in previous cropping cycle; B, soil solarization; $\mathbf{C}$, sanitation; and $\mathbf{D}$, distance to nearest infected unit (Bonferroni correction for multiple comparisons). In each graph, letters above bars represent significant differences at $P<0.05$. dependent variables, such as the agricultural practices employed and the management decisions made that might be attributed to the grower. The later hypothesis is supported by our results. The spatial scale we found $(1,500 \mathrm{~m})$ can be attributed to the grower, as we found that this spatial scale is similar to the average distance between grower's production units $(1,594 \mathrm{~m})$. This result supports the general conclusion but should be considered cautiously as the $1,500 \mathrm{~m}$ scale is constrained by the $500 \mathrm{~m}$ increment used. In addition, we found that the variable Farm had the highest independent contribution when using hierarchical partitioning. Additional support for this hypothesis came from the correlation analyses revealing that the overall explained variation increased considerably upon including Farm as a variable in the model. Interestingly, a much lower increase occurred when we used Village or County instead of Farm, further indicating the role of the grower affecting disease severity. This variable probably encompasses variation in experience and differences in implementing agricultural practices between farms. In this regard, the demonstration of a substantial effect of the grower should be emphasized because it indicates that some agricultural practices can reduce or increase the severity of the disease. Similar conclusions were reported previously for Alternaria leaf spot (caused by Alternaria macrospora) in Pima cotton (Shtienberg 1996).

The second aim of this study was to provide insight into the variables associated with the severity of $C$. michiganensis subsp. michiganensis. The results suggest that variables affecting primary inoculum inside or outside the production units had only minor effects on the severity of bacterial canker, whereas the variables affecting disease severity during the season were more influential on disease severity. This finding further supports the conclusion described above regarding the significance of the activities employed by the growers on disease severity.

C. michiganensis subsp. michiganensis survives in infected plant debris in the soil for months and even years (Basu 1970; Fatmi and Schaad 2002; Strider 1969; Yogev et al. 2009) and surviving bacterial cells may serve as primary inoculum for the preceding cropping cycle. This supports our finding that time interval between

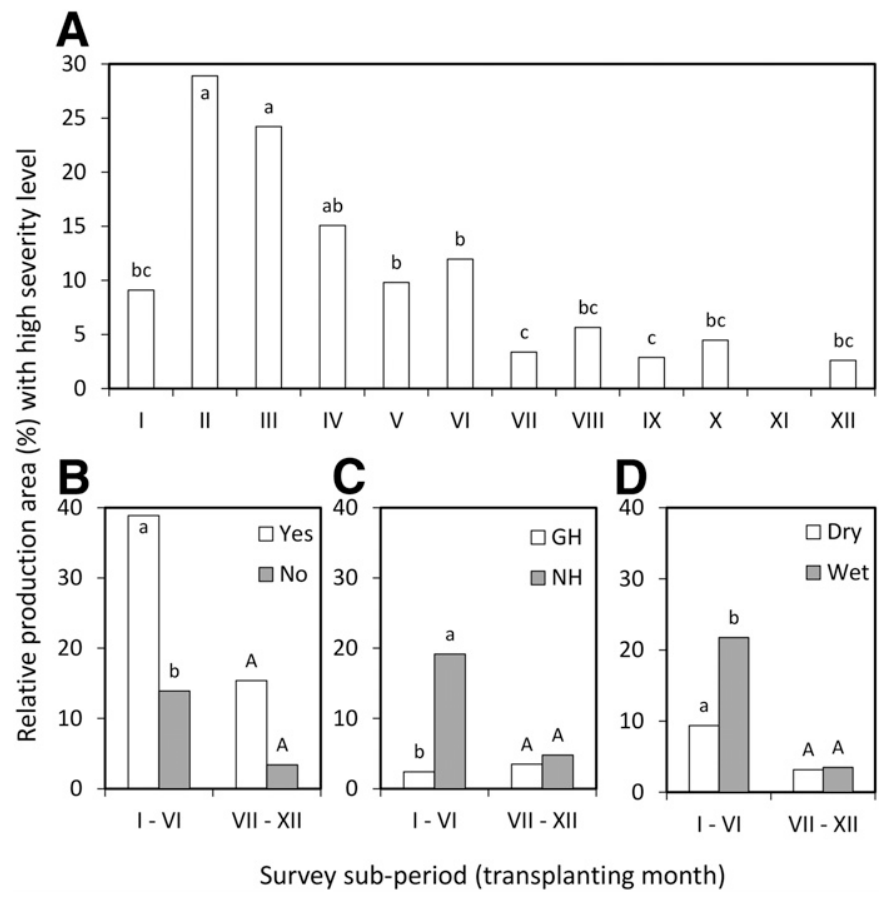

Fig. 5. Effects of the four significant variables from the third model on bacterial canker severity: A, month of transplanting (Bonferroni correction for multiple comparisons); $\mathbf{B}$, management practices; $\mathbf{C}$, type of structure $(\mathrm{GH}=$ greenhouse, $\mathrm{NH}=$ net-house); and $\mathbf{D}$, work only while plants were dry. $\mathbf{A}, \mathbf{C}$, and $\mathbf{D}$, Letters above bars represent significant differences at $P<0.05$. B, Letters represents significant differences at $P=0.0504$. 
cropping cycles was not significant. Nevertheless, our analysis revealed that in about $50 \%$ of the cases, disease was not observed at all in plants growing in production units that were severely diseased during the previous cropping cycle and in only $18 \%$ of the cases severe infections also developed in the preceding cropping cycle (Fig. 4A). This suggests that the ability of $C$. michiganensis subsp. michiganensis to survive in the soil serve as primary inoculum to the preceding cropping cycle and cause disease is variable (Chang et al. 1992; Gitaitis et al. 1991). Nevertheless, it is possible that plants in the preceding crops were colonized without exhibiting visible disease symptoms. It was observed that the yield of colonized, hence symptomless plants was not inferior to that of noncolonized, healthy plants (D. Shtienberg, unpublished data). The fact that a production unit is severely infected in one cropping cycle does not necessarily indicate that disease will also be severe in the next crop. We also found that severe infections developed in production units that were not diseased in the previous cropping cycle. Severe infections also developed in new production units and in production units where the previous crop was not tomatoes. Overall, these results indicate that the initial inoculum originated from external sources. The variable Pesticide was found to be not significant and although these chemicals are used by growers, they are not effective against $C$. michiganensis subsp. michiganensis.

Effect of the variable DistTrash was not significant. To our knowledge there is no documentation regarding wind dispersal of C. michiganensis subsp. michiganensis. However, distance to nearest infected production unit was found to be significant and generally it seems that proximity to infected production units increased the probability that a certain production unit will be diseased. A possible explanation might be that adjacent production units belong to the same farm, further signifying the role of the grower affecting disease severity.

C. michiganensis subsp. michiganensis is a seedborne pathogen and infected transplants are considered to be the main source of initial inoculum (Gitaitis et al. 1991; Kleitman et al. 2008). Nevertheless, in the second model effects of the variable Nursery, which presumably should have reflected this source of initial inoculum, was insignificant (Table 4). A possible explanation for the lack of significance of this variable is that all nurseries receive seeds of a certain cultivar from the same seed companies; thus, if seeds of a certain cultivar were infested with $C$. michiganensis subsp. michiganensis, these seeds were distributed to all nurseries that produced transplants of that cultivar and the analysis could not distinguish between them. This highlights the fact that analyzing large-scale survey data may identify the significant factors that encompass variation between samples but overlook (presumably important) factors with low variability between samples.

The month of transplanting had the highest independent effect in the variables group characterizing the effects of disease severity during the season. It seems that high disease infestation developed when transplanting was done in February to April compared with transplanting in the other months. These results suggest that the environmental conditions prevailing during the initial growth period significantly affect the development of $C$. michiganensis subsp. michiganensis and the intensity of disease symptoms. Sharabani et al. (2013) recently published that guttation promotes pathogen spread and infection and that the temperatures prevailing soon after infection affect disease severity (Sharabani et al. 2014). In Israel guttation is more abundant in early spring and spring temperatures are more favorable to the pathogen. In one of their experiments Sharabani et al. (2013) showed that when symptomless source plants wet with guttation droplets were touched, subsequent touching of near-by healthy plants spread the bacteria within rows, consequently increasing the disease severity within the production units. This could also explain the importance of working while plants are dry (WorkDry). In addition, we found that in net-houses the disease severity was higher. There are known differences in air and plant temperatures and solar radiation intensity inside the structure between greenhouses and net-houses that might affect disease occurrence and severity (Sethi et al. 2009). Differences between greenhouses and net-houses and the potential effect on the disease severity were not examined in this project.

Cultivar was the only variable in the third variables group that was not significant. This result was expected as currently, no commercial resistant tomato cultivars to $C$. michiganensis subsp. michiganensis are available (Sen et al. 2015). An unexpected result of our analysis is that more area was highly infected after implementing management practices. A potential explanation might be that these management practices were implemented only upon identifying disease symptoms in the production unit. An additional explanation might be that such actions might have been implemented when prior severity in the production unit was high which might suggest the presence of primary inoculum in the unit. However, most of these actions were found to be not very effective (D. Shtienberg, unpublished data).

Including the variable Farm as an explanatory variable in the models at least doubled the explained variability of disease severity. The variable Farm includes the growers experience, cultural practices, level of expertise, and meticulousness. Growers differ in their experience and professionalism. This influences their management decisions and the agricultural practices they employed and, in turn, their success in managing bacterial canker. The potential differences between growers were not fully identified in this work. This can be due to two possible explanations. According to the first explanation, there were differences in the quality of implementation of the management practices between the growers that were not revealed by our survey. An alternative explanation might be that other factors, that might be associated with the variable Farm and were not included in our analyses, could have a greater influence on disease severity. For example, it was shown that variables like growing media, fertilization, or irrigation affect plant physiology and thereby can impact disease progression and severity (Punja et al. 2007). Thus, a more detailed examination of the differences between growers, perhaps focusing on other aspects of the growing process, could identify other relevant variables.

\section{ACKNOWLEDGMENTS}

This study is part of the Khosen Clavibacter project, financed by the Israeli Ministry of Agriculture and Rural Development and by the Israeli Plants Production \& Marketing board. The work is a contribution of the Agricultural Research Organization, Volcani Center, Bet Dagan, Israel, No. $553 / 15$

\section{LITERATURE CITED}

Aguayo, J., Elegbede, F., Husson, C., Saintonge, F.-X., and Marçais, B. 2014. Modeling climate impact on an emerging disease, the Phytophthora alniinduced alder decline. Glob. Change Biol. 20:3209-3221.

Basu, P. 1970. Temperature, an important factor determining survival of Corynebacterium michiganense in soil. Phytopathology 60:825-827.

Bivand, R., Anselin, L., Berke, O., Bernat, A., Carvalho, M., Chun, Y., Dormann, C. F., Dray, S., Halbersma, R., and Lewin-Koh, N. 2011. spdep: Spatial dependence: Weighting schemes, statistics and models. R package version $0.5-56$.

Campbell, C. L., and Madden, L. V. 1990. Introduction to Plant Disease Epidemiology. John Wiley \& Sons, New York.

Chang, R. J., Ries, S. M., and Pataky, J. K. 1992. Effects of temperature, plant age, inoculum concentration, and cultivar on the incubation period and severity of bacterial canker of tomato. Plant Dis. 76:1150-1155.

Dormann, C. F., McPherson, J. M., Araújo, M. B., Bivand, R., Bolliger, J., Carl, G., Davies, R. G., Hirzel, A., Jetz, W., and Kissling, D. W. 2007. Methods to account for spatial autocorrelation in the analysis of species distributional data: A review. Ecography 30:609-628.

Eichenlaub, R., and Gartemann, K. H. 2011. The Clavibacter michiganensis subspecies: Molecular investigation of Gram-positive bacterial plant pathogens. Annu. Rev. Phytopathol. 49:445-464. 
ESRI. 2015. Incremental Spatial Autocorrelation. ArcGIS. Published online. http://resources.arcgis.com/en/help/main/10.1/index.html\#/Incremental_Spatial_ Autocorrelation/005p0000004z000000/

Fatmi, M., and Schaad, N. W. 2002. Survival of Clavibacter michiganensis ssp. michiganensis in infected tomato stems under natural field conditions in California, Ohio and Morocco. Plant Pathol. 51:149-154.

Gitaitis, R. D., Beaver, R. W., and Voloudakis, A. E. 1991. Detection of Clavibacter michiganensis subsp. michiganensis in symptomless tomato transplants. Plant Dis. 75:834-838.

Gleason, M. L., Braun, E. J., Carlton, W. M., and Peterson, R. H. 1991. Survival and dissemination of Clavibacter michiganensis subsp. michiganensis in tomatoes. Phytopathology 81:1519-1523.

Gleason, M. L., Gitaitis, R. D., and Ricker, M. D. 1993. Recent progress in understanding and controlling bacterial canker of tomato in eastern North America. Plant Dis. 77:1069-1076.

Graham, M. H. 2003. Confronting multicollinearity in ecological multiple regression. Ecology 84:2809-2815.

Kalkhan, M. A. 2011. Spatial Statistics: Geospatial Information Modeling and Thematic Mapping. CRC Press, Boca Raton, FL.

Kleitman, F., Barash, I., Burger, A., Iraki, N., Falah, Y., Sessa, G., Weinthal, D., Chalupowicz, L., Gartemann, K.-H., and Eichenlaub, R. 2008. Characterization of a Clavibacter michiganensis subsp. michiganensis population in Israel. Eur. J. Plant Pathol. 121:463-475.

Kundu, S., Aulchenko, Y. S., van Duijn, C. M., and Janssens, A. C. J. 2011. PredictABEL: An R package for the assessment of risk prediction models. Eur. J. Epidemiol. 26:261-264.

Lamichhane, J. R., Fabi, A., and Varvaro, L. 2014. Summer heat and low soil organic matter influence severity of hazelnut cytospora canker. Phytopathology 104:387-395.

Legendre, P., and Legendre, L. 2012. Numerical Ecology, 3rd English edition. Elsevier, Amsterdam.

MacNally, R., and Walsh, C. J. 2004. Hierarchical partitioning public-domain software. Biodivers. Conserv. 13:659-660.

Meentemeyer, R. K., Haas, S. E., and Václavík, T. 2012. Landscape epidemiology of emerging infectious diseases in natural and human-altered ecosystems. Annu. Rev. Phytopathol. 50:379-402.

Moran, P. A. 1950. Notes on continuous stochastic phenomena. Biometrika 37: 17-23.

Nagelkerke, N. J. 1991. A note on a general definition of the coefficient of determination. Biometrika 78:691-692.

Pierre, J. P., Abolt, C. J., and Young, M. H. 2014. Impacts from aboveground activities in the Eagle Ford Shale play on landscapes and hydrologic flows, La Salle County, Texas. Environ. Manage. 55: 1262-1275.

Punja, Z. K., De Boer, S. H., and Sanfaçon, H. 2007. Biotechnology and Plant Disease Management. Hardback Publishers, New York.
Rouhani, S., Srivastava, R. M., Desbarats, A. J., Cromer, M. V., and Johnson, A. I. 1996. Geostatistics for Environmental and Geotechnical Applications. ASTM International, West Conshohocken, PA.

Sen, Y., van der Wolf, J., Visser, R. G., and van Heusden, S. 2015. Bacterial canker of tomato: Current knowledge of detection, management, resistance, and interactions. Plant Dis. 99:4-13.

Sethi, V. P., Dubey, R. K., and Dhath, A. S. 2009. Design and evaluation of modified screen net house for off-season vegetable raising in composite climate. Energy Convers. Manage. 50:3112-3128.

Sharabani, G., Manulis-Sasson, S., Borenstein, M., Shulhani, R., Lofthouse, M., Chalupowicz, L., and Shtienberg, D. 2013. The significance of guttation in the secondary spread of Clavibacter michiganensis subsp. michiganensis in tomato greenhouses. Plant Pathol. 62:578-586.

Sharabani, G., Manulis-Sasson, S., Chalupowicz, L., Borenstein, M., Shulhani, R., Lofthouse, M., Sofer, M., Frenkel, O., Dror, O., and Shtienberg, D. 2014. Temperature at the early stages of Clavibacter michiganensis subsp. michiganensis infection affects bacterial canker development and virulence gene expression. Plant Pathol. 63:1119-1129.

Shlevin, E., Mahrer, Y., Kritzman, G., and Katan, J. 2004. Survival of plant pathogens under structural solarization. Phytoparasitica 32:470-478.

Shtienberg, D. 1996. Variables associated with intensity of Alternaria leaf spot in Pima cotton. Phytopathology 86:123-128.

Strider, D. L. 1967. Survival studies with the tomato bacterial canker organism. Phytopathology 57:1067-1071.

Strider, D. L. 1969. Bacterial canker of tomato caused by Corynebacterium michiganense; A literature review and bibliography. N.C. Agric. Exp. Stn. Tech. Bull. 193.

Tan, S. Y., and Li, J. 2014. An exploratory spatial analysis of soil organic carbon distribution in Canadian eco-regions. ISPRS-Int. Arch. Photogramm. Remote Sens. Spat. Inf. Sci. XL-2:205-212.

Tapparo, A., Giorio, C., Marzaro, M., Marton, D., Soldà, L., and Girolami, V. 2011. Rapid analysis of neonicotinoid insecticides in guttation drops of corn seedlings obtained from coated seeds. J. Environ. Monit. 13:1564-1568.

Thébaud, G., Sauvion, N., Chadøeuf, J., Dufils, A., and Labonne, G. 2006. Identifying risk factors for European stone fruit yellows from a survey. Phytopathology 96:890-899.

Trangmar, B. B., Yost, R. S., and Uehara, G. 1985. Application of geostatistics to spatial studies of soil properties. Adv. Agron. 38:45-94.

Volcani, Z. 1985. Bacterial Diseases of Plants in Israel. Agricultural Research Organization, Bet Dagan, Israel.

Wang, H., Hall, C. A., Cornell, J. D., and Hall, M. H. 2002. Spatial dependence and the relationship of soil organic carbon and soil moisture in the Luquillo Experimental Forest, Puerto Rico. Landscape Ecol. 17:671-684.

Yogev, A., Raviv, M., Kritzman, G., Hadar, Y., Cohen, R., Kirshner, B., and Katan, J. 2009. Suppression of bacterial canker of tomato by composts. Crop Prot. 28:97-103. 